\title{
Neutrophil Gelatinase-Associated Lipocalin Levels in Early and Late Onset Preeclampsia
}

\author{
Onur GURALP', Nevin TUTEN², Mahmut ONCUL ${ }^{3}$, Serdar ACIKGOZ ${ }^{3}$, Hakan EKMEKCI ${ }^{4}$, Abdullah TUTEN \\ Oldenburg, Germany
}

\begin{abstract}
OBJECTIVE: To evaluate the serum neutrophil gelatinase-associated lipocalin levels in pregnant women with and without preeclampsia, early-onset preeclampsia and late-onset preeclampsia, preeclampsia with and without severe features, and investigate the correlation with the neonatal outcomes.
\end{abstract}

STUDY DESIGN: A total of 79 pregnant women, 27 with uncomplicated pregnancies, 30 with early-onset preeclampsia, and 22 with late-onset preeclampsia were evaluated in a cross-sectional study. Neutrophil gelatinase-associated lipocalin was measured with a colorimetric Sandwich-ELISA method. Age; body mass index; systolic and diastolic blood pressure; umbilical-artery Doppler results; serum urea, bilirubin, uric acid, AST, ALT; 24-hour protein test; birth-weight; and Apgar-scores were recorded.

RESULTS: Serum neutrophil gelatinase-associated lipocalin levels were significantly higher in women with preeclampsia compared to those without preeclampsia $(p<0.001)$; in women with early-onset preeclampsia compared to those with late-onset preeclampsia $(p<0.001)$; and in women with late-onset preeclampsia compared to those without preeclampsia $(p=0.028)$. Mean serum neutrophil gelatinase-associated lipocalin levels were comparable in women with preeclampsia with and without severe features $(p=0.076)$. The correlation analysis showed that neutrophil gelatinase-associated lipocalin was not affected by age or body mass index. Neutrophil gelatinase-associated lipocalin had a positive correlation with systolic and diastolic blood pressure and the umbilical-artery PI and RI. Serum neutrophil gelatinase-associated lipocalin had a positive correlation with serum urea $(r=0.416, p=0.031)$ however had no significant correlation with birth-weight, Apgar-scores, uric acid and amount of proteinuria in women with preeclampsia.

CONCLUSION: Serum neutrophil gelatinase-associated lipocalin levels were significantly higher in women with preeclampsia compared to those without preeclampsia; in women with early-onset preeclampsia compared to those with late-onset preeclampsia, and in women with late-onset preeclampsia compared to women without preeclampsia. Mean serum neutrophil gelatinase-associated lipocalin levels were comparable in women with preeclampsia with and without severe features.

Keywords: Preeclampsia, Preeclampsia with severe features, Proteinuria, Umbilical artery doppler

Gynecol Obstet Reprod Med 2020;26(3):166-172

${ }^{1}$ Carl von Ossietzky Oldenburg University, Department of Obstetrics and Gynecology, Oldenburg, Germany

2 Darende State Hospital, Obstetrics and Gynecology, Malatya, Turkey

${ }^{3}$ Istanbul Cerrahpasa University Department of Obstetrics and Gynecology, Fatih, Istanbul, Turkey

${ }^{4}$ Istanbul Cerrahpasa University, Department of Biochemistry, Fatih, Istanbul, Turkey

Address of Correspondence: Onur Guralp

Department of Obstetrics and Gynecology, Klinikum Oldenburg, AöR

Carl von Ossietzky Oldenburg

University, Rahel-Strauß-Straße 10,

26133, Oldenburg, Germany

onur.gueralp@uni-oldenburg.de

Submitted for Publication: Accepted for Publication:

ORCID IDs of the authors: NT:0000-0001-8609-4770 SA:0000-0001-9355-7753 AT:0000-0002-8495-6426

\begin{tabular}{|c|c|}
\hline \multirow{3}{*}{ 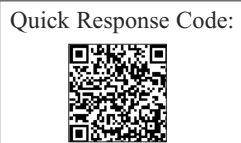 } & Access this article online \\
\hline & $\begin{array}{l}\text { Website: www.gorm.com.tr } \\
\text { e- mail: info@gorm.com.tr }\end{array}$ \\
\hline & DOI:10.21613/GORM.2018.918 \\
\hline
\end{tabular}

\section{Introduction}

Preeclampsia is classically defined as hypertension and proteinuria usually developing after $20^{\text {th }}$ gestational week. New definitions also include maternal organ dysfunction, such as renal insufficiency, liver involvement, neurological or hematological complications (1). 6 - $8 \%$ of all pregnancies are complicated with preeclampsia (2).

Considering the pathogenesis and maternal and fetal complications related to preeclampsia, it is further classified as early-onset preeclampsia (EOPE) and late-onset preeclampsia (LOPE) with the onset of preeclampsia taking place $<34$ weeks and $\geq 34$ weeks respectively (3). EOPE is encountered in $1 / 5$ of all cases, nevertheless, it is associated with $4 / 5$ of the complications related to preeclampsia $(4,5)$.

Neutrophil gelatinase-associated lipocalin (NGAL) is found in many human cell types such as neutrophils, liver cells, kidney, and fat tissue. NGAL may function as a trans-

How to cite this article: Guralp O. Tuten N. Oncul M. Acikgoz S. Ekmekci H. Tuten A. Neutrophil Gelatinase-Associated Lipocalin Levels in Early and Late Onset Preeclampsia. Gynecol Obstet Reprod Med. 2020;26(3):166-172 
port vehicle for many small molecules between neighbor cells (6). It may also function as an acute-phase protein. Haase et al. (7) and Mishra et al. (8) have shown that NGAL is increased in acute renal injury.

Kim et al. (6) have detected that plasma NGAL levels were increased in women with preeclampsia compared to normotensive controls. Moreover, Scazzochio et al. (9) have shown that the elevated plasma NGAL levels are associated with increased risk of maternal complications in women with severe EOPE.

The kidney damage and proteinuria and endothelial inflammatory reactions in preeclampsia constitute the basis of the idea that NGAL may play a role in the pathogenesis of preeclampsia. In our study, we evaluated the serum NGAL levels in women with and without preeclampsia, EOPE and LOPE, preeclampsia with and without severe features, and investigated the correlation with the neonatal outcomes.

\section{Material and Method}

A total of 79 pregnant women, 27 with normal pregnancy, 30 with EOPE, and 22 with LOPE, who were diagnosed between January 2016 and December 2016 at the Istanbul University, Cerrahpasa School of Medicine Istanbul, Turkey were evaluated in a cross-sectional study. Informed consent was obtained from all women, participating in this study and the study protocol was approved by the Ethics Committee of Istanbul University, Cerrahpasa Faculty of Medicine.

Preeclampsia was defined as the new onset of hypertension (on two occasions at least $4 \mathrm{~h}$ apart, systolic and/or diastolic blood pressure of $140 \mathrm{and} /$ or $90 \mathrm{mmHg}$ ) after the $20^{\text {th }}$ week of pregnancy concomitant proteinuria $(300 \mathrm{mg}$ in a $24-\mathrm{h}$ urine or $1(+)$ protein by dipstick test on two random urine samples) (10). Women with gestational hypertension in the absence of proteinuria are diagnosed with preeclampsia if they present with any of the following severe features: thrombocytopenia (platelet count $<100,000 \times 10^{9} / \mathrm{L}$ ); impaired liver function as indicated by abnormally elevated blood concentrations of liver enzymes (to twice the upper limit of normal concentration); severe persistent right upper quadrant or epigastric pain and not accounted for by alternative diagnoses; renal insufficiency (serum creatinine concentration $>1.1 \mathrm{mg} / \mathrm{dL}$ or a doubling of the serum creatinine concentration in the absence of other renal disease); pulmonary edema; or new-onset headache unresponsive to acetaminophen and not accounted for by alternative diagnoses or visual disturbances (1).

The women with preeclampsia were further divided into subgroups:

EOPE (onset of preeclampsia $<34$ weeks +0 days) and LOPE (onset of preeclampsia $\geq 34$ weeks +0 days) (3).

Preeclampsia with severe features (formerly "severe preeclampsia") was defined as: After 20 weeks of gestation in previously normotensive women who develop: (1)
- Systolic blood pressure $\geq 160 \mathrm{mmHg}$ or diastolic blood pressure $\geq 110 \mathrm{mmHg}$ and proteinuria (with or without signs and symptoms of significant end-organ dysfunction).

- Systolic blood pressure $\geq 140 \mathrm{mmHg}$ or diastolic blood pressure $\geq 90 \mathrm{mmHg}$ (with or without proteinuria) and one or more of the following signs and symptoms of significant end-organ dysfunction:

- New-onset cerebral or visual disturbance, such as photopsia (flashes of light) and/or scotomata (dark areas or gaps in the visual field); severe headache or headache that persists and progresses despite analgesic therapy; altered mental status.

- Severe, persistent right upper quadrant or epigastric pain unresponsive to medication and not accounted for by an alternative diagnosis or serum transaminase concentration $\geq 2$ times upper limit of normal for a specific laboratory, or both.

- $<100,000$ platelets/ $\mu \mathrm{L}$.

- Progressive renal insufficiency (serum creatinine $>1.1$ $\mathrm{mg} / \mathrm{dL}[97.3 \mu \mathrm{mol} / \mathrm{L}]$

- Pulmonary edema

The inclusion criteria for the control group included singleton uncomplicated pregnancies between 28 and $35 \mathrm{GW}$ at the time of blood sampling, with fetuses appropriate for gestational age and delivery after $370 \mathrm{GW}$. Gestational age was calculated according to the first day of the last menstrual period or a first-trimester ultrasound measurement of the crownrump length (CRL).

Exclusion criteria for both preeclamptic and nonpreeclamptic groups included multiple pregnancies, known fetal anomalies, maternal chronic illnesses, preexisting hypertensive disorders, preterm labor, and diabetes (all types of DM and gestational diabetes) premature rupture of membranes, chorioamnionitis and other known systemic inflammatory disorders.

Venous blood samples were obtained from patients in the study group on admission, before the onset of the labor. The control group was selected from pregnant women who had their routine outpatient pregnancy care between 28 and 35 GW in our hospital. Peripheral blood samples were collected in EDTA or serum tubes and centrifuged for $15 \mathrm{~min}$ at $1000 \mathrm{~g}$ at $2-8{ }^{\circ} \mathrm{C}$ within $30 \mathrm{~min}$ of collection. Upper serum or plasma phase was collected and frozen at $80^{\circ} \mathrm{C}$ before further analysis. Complete blood count and biochemical analyses were performed immediately.

Complete blood count, serum creatinine, AST (aspartate aminotransferase), ALT (alanine aminotransferase), uric acid and urea and 24-hour urinary protein excretion were evaluated using routine biochemistry analyzer (Beckman Coulter AU 2700 , USA). Protein excretion in spot urine analysis were performed for all participants in the control group.

Doppler measurements were performed by the same obstetrician (A.T.) for all study patients using Voluson 730 Pro ultrasound machines (GE Healthcare, Zipf, Austria). 
Neutrophil gelatinase-associated lipocalin was measured with a colorimetric Sandwich-ELISA method using the commercial kits (Human NGAL ELISA Kit Cat. No: E-ELH0096, sandwich-Ab-ELISA-Elabscience, Houston, Texas). The optical density (OD) was measured spectrophotometrically at a wavelength of $450 \mathrm{~nm} \pm 2 \mathrm{~nm}$. Detection range was $0.16-10 \mathrm{ng} / \mathrm{m}$ Land the sensitivity was $0.10 \mathrm{ng} / \mathrm{mL}$.

The sample size was calculated as described by Viechtbauer et al. (11). A confidence interval of $95 \%$ and a probability/prevalence of preeclampsia of $10 \%$ was used. The smallest sample size for the preeclampsia group was found to be 28 women.

All analyses were performed using the Statistical Package for the Social Sciences (SPSS) software version 18.0 (SPSS Inc., Chicago, IL). The Kolmogorov- Smirnov test was used to assess the normality of the distribution of variables. Data were presented as mean \pm standard deviation (SD). The Comparison between groups was performed using either an independent samples t-test or a Chi-square test depending on the variable. Pearson correlation analysis was performed to evaluate correlations between parametric variables. A p value of $<0.05$ was accepted as statistically significant.

\section{Results}

A total of 79 women were included in the statistical evaluation. There were 52 women with preeclampsia and 27 women without preeclampsia. The demographic, clinical and laboratory features of the women with and without preeclamp- sia were given in table I. The distributions of all parameters were homogeneous. There was no significant difference regarding age, body-mass-index (BMI) and parity between the two groups.

Mean gestational age at diagnosis of preeclampsia was $32.1 \pm 3.9$ weeks' gestation. Systolic and diastolic blood pressure were significantly higher in women with preeclampsia as expected. The umbilical artery PI and RI were significantly higher in women with preeclampsia compared to the women without preeclampsia $(1.0 \pm 0.3$ vs $0.7 \pm 0.1, p<0.001$; and $0.6 \pm 0.1$ vs $0.5 \pm 0.05, p<0.001$; respectively). Serum NGAL was significantly higher in women with preeclampsia compared to the women without preeclampsia $(21.5 \pm 2.5 \mathrm{ng} / \mathrm{mL}$ vs $18.2 \pm 0.9 \mathrm{ng} / \mathrm{mL}, p<0.001)$. The range of serum NGAL in all subjects was $15.26-26.03 \mathrm{ng} / \mathrm{mL}$.

The demographic, clinical and laboratory features of the women with EOPE and LOPE were given in table II. There was no significant difference regarding age, body-mass-index (BMI), parity, systolic and diastolic blood pressure, and the umbilical artery PI and RI between the two groups. Serum NGAL was significantly higher in women with EOPE compared to the women with LOPE $(23.3 \pm 1.3 \mathrm{ng} / \mathrm{mL}$ vs $18.9 \pm 1.1$ $\mathrm{ng} / \mathrm{mL}, p<0.001)$. Additionally, serum NGAL was significantly higher in women with LOPE compared to the women without preeclampsia $(18.9 \pm 1.1 \mathrm{ng} / \mathrm{mL}$ vs $18.2 \pm 0.9 \mathrm{ng} / \mathrm{mL}$, $p=0.028)$. The serum NGAL levels in women without preeclampsia and women with EOPE and LOPE were presented in boxplot analysis (Figure 1).

Table I: Demographic, clinical and laboratory features of the women with and without preeclampsia

\begin{tabular}{|c|c|c|c|}
\hline & $\begin{array}{c}\text { Preeclampsia } \\
(\text { Mean } \pm \text { SD })(n=52)\end{array}$ & $\begin{array}{l}\text { Non-preeclampsia } \\
(\text { Mean } \pm \text { SD) }(n=27)\end{array}$ & $p$ \\
\hline Age (years) & $30.0 \pm 5.4$ & $30.7 \pm 5.0$ & 0.518 \\
\hline BMI $\left(\mathrm{kg} / \mathrm{m}^{2}\right)$ & $31.1 \pm 5.7$ & $29.6 \pm 3.2$ & 0.160 \\
\hline Gravidity (n) & $2.2 \pm 1.5$ & $2.1 \pm 1.6$ & 0.848 \\
\hline Parity $(n)$ & $0.9 \pm 1.0$ & $0.7 \pm 1.5$ & 0.604 \\
\hline Systolic arterial blood pressure $(\mathrm{mm} / \mathrm{Hg})$ & $156.1 \pm 19.1$ & $109.3 \pm 9.1$ & $<0.001$ \\
\hline Diastolic arterial blood pressure $(\mathrm{mm} / \mathrm{Hg})$ & $101.2 \pm 14.4$ & $68.4 \pm 8.4$ & $<0.001$ \\
\hline Umbilical artery PI & $1.0 \pm 0.3$ & $0.7 \pm 0.1$ & $<0.001$ \\
\hline Umbilical artery RI & $0.6 \pm 0.1$ & $0.5 \pm 0.05$ & $<0.001$ \\
\hline NGAL (ng/mL) & $21.5 \pm 2.5$ & $18.2 \pm 0.9$ & $<0.001$ \\
\hline GA at birth $(w)$ & $33.2 \pm 3.6$ & $39.1 \pm 1.4$ & $<0.001$ \\
\hline GA at sampling (w) & $32.2 \pm 3.8(25-39)$ & $31.9 \pm 1.8(28-35)$ & 0.699 \\
\hline Weight at birth (g) & $1755 \pm 774$ & $3270 \pm 370$ & $<0.001$ \\
\hline Apgar $1 \mathrm{~min}$ & $6.0 \pm 1.6$ & $7.5 \pm 0.9$ & $<0.001$ \\
\hline Apgar 5 min & $7.5 \pm 1.3$ & $8.6 \pm 0.7$ & $<0.001$ \\
\hline Platelet count $\left(10^{3} / \mu \mathrm{L}\right)$ & $185 \pm 68$ & $196 \pm 54$ & 0.410 \\
\hline Creatinine $(\mathrm{mg} / \mathrm{dL})$ & $0.65 \pm 0.23$ & $0.57 \pm 0.07$ & 0.037 \\
\hline Total bilirubin (mg/dL) & $0.31 \pm 0.23$ & $0.31 \pm 0.23$ & 0.650 \\
\hline Uric acid (mg/dL) & $6.7 \pm 1.1$ & $1.18 \pm 0.39$ & $<0.001$ \\
\hline Urea $(\mathrm{mg} / \mathrm{dL})$ & $29.4 \pm 9.7$ & $17.3 \pm 6.3$ & $<0.001$ \\
\hline AST (IU/L) & $32.6 \pm 19.1$ & $19.4 \pm 6.5$ & $<0.001$ \\
\hline ALT (IU/L) & $29.6 \pm 34.1$ & $14.5 \pm 5.6$ & 0.002 \\
\hline
\end{tabular}

GA: Gestational age, NGAL: Neutrophil gelatinase-associated lipocalin, PI: Pulsatility index, RI: Resistance index, $p<0.05$ is significant 
Table II: Demographic, clinical and laboratory features of the women with early- and late-onset preeclampsia

\begin{tabular}{|c|c|c|c|}
\hline & $\begin{array}{l}\text { Early onset preeclampsia } \\
\quad(\text { Mean } \pm \text { SD) }(n=30)\end{array}$ & $\begin{array}{l}\text { Late-onset preeclampsia } \\
\quad(\text { Mean } \pm \text { SD) }(n=22)\end{array}$ & $p$ \\
\hline Age (years) & $30.0 \pm 5.8$ & $30.0 \pm 4.9$ & 1.000 \\
\hline BMI $\left(\mathrm{kg} / \mathrm{m}^{2}\right)$ & $30.9 \pm 5.0$ & $31.4 \pm 6.7$ & 0.757 \\
\hline Gravidity (n) & $2.0 \pm 1.4$ & $2.5 \pm 1.5$ & 0.224 \\
\hline Parity $(n)$ & $0.7 \pm 1.0$ & $1.1 \pm 1.0$ & 0.238 \\
\hline Systolic arterial blood pressure $(\mathrm{mm} / \mathrm{Hg})$ & $158.0 \pm 17.5$ & $153.7 \pm 21.2$ & 0.414 \\
\hline Diastolic arterial blood pressure $(\mathrm{mm} / \mathrm{Hg})$ & $101.9 \pm 13.0$ & $100.4 \pm 16.2$ & 0.702 \\
\hline Umbilical artery PI & $1.1 \pm 0.2$ & $0.9 \pm 0.3$ & 0.066 \\
\hline Umbilical artery RI & $0.6 \pm 0.1$ & $0.6 \pm 0.1$ & 0.034 \\
\hline NGAL $(n g / m L)$ & $23.3 \pm 1.3$ & $18.9 \pm 1.1$ & $<0.001$ \\
\hline GA at birth (w) & $30.6 \pm 2.3$ & $36.6 \pm 1.2$ & $<0.001$ \\
\hline GA at sampling (w) & $29.1 \pm 2.2(25-33)$ & $35.9 \pm 1.5(35-39)$ & $<0.001$ \\
\hline Weight at birth $(\mathrm{g})$ & $1280 \pm 370$ & $2370 \pm 729$ & $<0.001$ \\
\hline Apgar $1 \mathrm{~min}$ & $5.2 \pm 1.3$ & $7.0 \pm 1.5$ & $<0.001$ \\
\hline Apgar $5 \mathrm{~min}$ & $6.9 \pm 1.1$ & $8.4 \pm 1.1$ & $<0.001$ \\
\hline Platelet count $\left(10^{3} / \mu \mathrm{L}\right)$ & $200 \pm 51$ & $165 \pm 82$ & 0.073 \\
\hline Creatinine $(\mathrm{mg} / \mathrm{dL})$ & $0.67 \pm 0.30$ & $0.62 \pm 0.06$ & 0.389 \\
\hline Total bilirubin (mg/dL) & $0.39 \pm 0.34$ & $0.27 \pm 0.11$ & 0.137 \\
\hline Uric acid $(\mathrm{mg} / \mathrm{dL})$ & $2.64 \pm 3.59$ & $1.83 \pm 0.38$ & $<0.001$ \\
\hline Urea $(\mathrm{mg} / \mathrm{dL})$ & $32.1 \pm 10.7$ & $25.9 \pm 7.0$ & 0.013 \\
\hline 24-hours urine protein test (mg/d) & $1000 \pm 599$ & $1104 \pm 1215$ & 0.747 \\
\hline AST (IU/L) & $34.9 \pm 21.0$ & $29.7 \pm 16.3$ & 0.327 \\
\hline ALT (IU/L) & $34.5 \pm 42.4$ & $29.7 \pm 16.3$ & 0.228 \\
\hline
\end{tabular}

NGAL: Neutrophil gelatinase-associated lipocalin, PI: Pulsatility index, RI: Resistance index, $p<0.05$ is significant

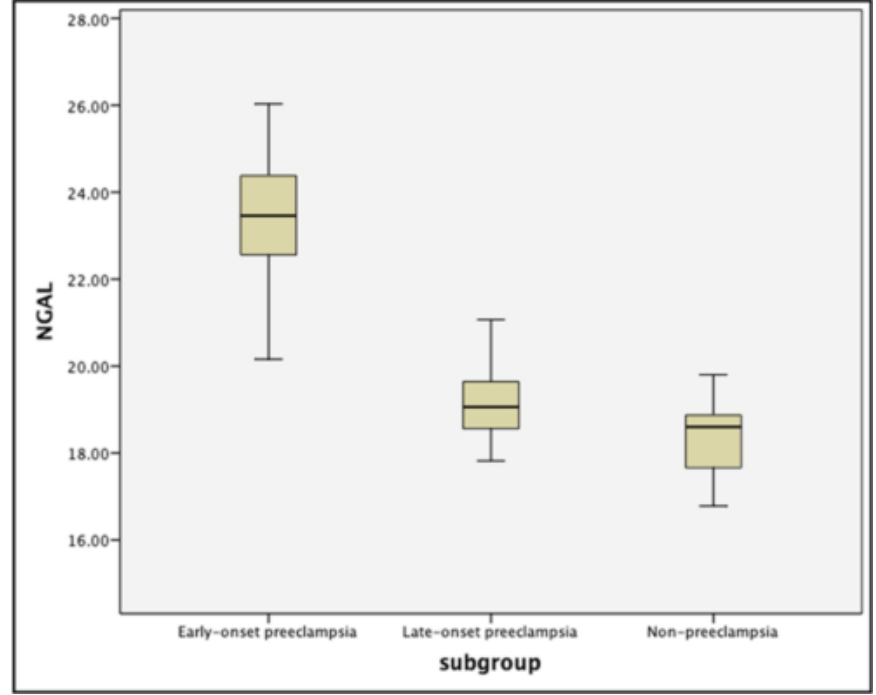

Figure 1: Boxplot analysis of the serum NGAL levels in women without preeclampsia and women with EOPE and LOPE

The women with preeclampsia were also divided into two other subgroups as preeclampsia without severe features $(n=28)$ and with severe features $(n=23)$. Serum NGAL levels were $22.2 \pm 2.1$ and $20.9 \pm 2.6 \mathrm{ng} / \mathrm{mL}$ in women with preeclampsia with and without severe features, respectively. $(p=0.076)$.

The correlation analysis showed that NGAL had no correlation with age or BMI in all women. However, NGAL had a positive correlation with systolic and diastolic blood pressure $(\mathrm{r}=0.513, p<0.001$ and $\mathrm{r}=0.484, p<0.001)$ and the umbilical artery PI and RI $(\mathrm{r}=0.376, p=0.001$ and $\mathrm{r}=0.395, p<0.001)$ (Table III).

Table III: Correlation test between NGAL and other parameters in all women

\begin{tabular}{llr}
\hline & NGAL & p-value \\
\hline Age & -0.098 & 0.393 \\
BMI & 0.159 & 0.165 \\
Systolic arterial blood pressure & $0.513^{* *}$ & $<0.001$ \\
Diastolic arterial blood pressure & $0.484^{* *}$ & $<0.001$ \\
Umbilical artery PI & $0.376^{* *}$ & $\mathbf{0 . 0 0 1}$ \\
Umbilical artery RI & $0.395^{* *}$ & $<0.001$ \\
\hline
\end{tabular}

Serum NGAL had a positive correlation with serum urea $(\mathrm{r}=0.416, \mathrm{p}=0.031)$ however had no significant correlation with birth-weight, Apgar scores, uric acid and amount of proteinuria in women with preeclampsia.

\section{Discussion}

In our study, serum NGAL was significantly higher in women with preeclampsia compared to women without preeclampsia. Moreover, serum NGAL was significantly higher in women with EOPE compared to the women LOPE. Mean serum NGAL levels were comparable in women with preeclampsia with and without severe features. The correlation analysis showed that NGAL was not affected by age or BMI. NGAL had a positive correlation with systolic and diastolic blood pressure and the umbilical artery PI and RI. 
Edelstam et al. (12) have shown that NGAL level is stable between 33 and $39 \mathrm{GW}$ and increases from $39 \mathrm{GW}$ on in healthy pregnant women. In order to reduce or eliminate the influence of gestational age on measurements, we took the blood samples in the non-preeclampsia group between 28 and 35 gestational weeks $(31.9 \pm 1.8 \mathrm{w})$. The mean gestational age at sampling was $32.2 \pm 3.8 \mathrm{w}(25-39 \mathrm{w})$ in the overall preeclampsia group, and $29.1 \pm 2.2 \mathrm{w}(25-33 \mathrm{w})$ in the earlyonset and $35.9 \pm 1.5 \mathrm{w}(35-39 \mathrm{w})$ in the late-onset preeclampsia groups. Regarding the results of the study of Edelstam et al. (12), it is expected that NGAL increases in the third trimester in a healthy pregnancy. However, in our study, serum NGAL was highest in the EOPE group, followed by LOPE group and non-preeclampsia group. This indicates the highly significant rise in the EOPE group despite earlier sampling.

D'Anna et al. evaluated NGAL levels during pregnancy in a series of studies in 2008 (13), 2009 (14), 2010 (15) and 2011 (16). They detected that NGAL was increased in preeclampsia compared to healthy pregnant women, probably due to the induction of leukocyte-mediated inflammatory activity and endothelial activation (13). However, they did not find any significant difference between early- and late-onset preeclampsia groups (13). They suggested that endothelial damage may be independent of the timing of the onset of preeclampsia. In later studies, they have shown that first trimester elevated serum NGAL levels could predict LOPE and early endothelial damage $(14,16)$. They concluded that the positive correlation between proteinuria and NGAL originated from renal injury (15).

Similar to D'Anna et al. (14), Youssef et al. (17) evaluated serum NGAL levels during pregnancy and have shown that combination of the first-trimester serum NGAL measurement and uterine artery Doppler, serum PAPP-A, PIGF, P-Selectin, sFLT-1 could improve the predictive value for late-onset preeclampsia. Karampas et al. (18) have shown that a combination of the first and second-trimester uterine artery pulsatility index (UtA-PI), ductus venosus pulsatility index (DV-PI) and a marker panel including PAPP-A, PIGF, sFlt-1, s-Flt1/PIGF, ADMA, MMP-9, MMP-9/NGAL may improve the detection of preeclampsia.

In our study, similar to the results of D'Anna et al. (13), we have found that the serum NGAL level was higher in women with preeclampsia compared to the control group, however, we detected a significant difference between the EOPE and LOPE groups. In early-onset preeclampsia, placental pathology is in the foreground, which causes maternal endothelial damage. For that reason, we may suggest that the endothelial damage marker NGAL is expected to be higher in EOPE. Stepan et al. (19) have shown that serum NGAL was significantly higher in women with EOPE compared to uncomplicated pregnancy. Scazzochio et al. (9) have shown that serum NGAL was significantly higher in women with early-onset severe preeclampsia compared to uncomplicated pregnancy. Maternal complications such as HELLP were more common with serum NGAL levels above $100 \mathrm{ng} / \mathrm{mL}$, although neonatal complications were comparable. In our study, serum NGAL levels had a range of $15.26-26.03 \mathrm{ng} / \mathrm{mL}$ with a homogenous distribution. These mean values were far below the values reported by Scazzochio et al. (9). We did not have any maternal complications such as HELLP or eclampsia.

Wang et al. (20) detected that the serum NGAL levels were significantly higher in women with severe preeclampsia compared to the control group. Dogan et al. (21) could not find any significant difference regarding serum NGAL levels between preeclamptic women and control group. In our study, serum NGAL levels were also comparable in preeclampsia with and without severe features groups.

Serum NGAL evaluation according to the severity of preeclampsia is important to understand the role of NGAL in preeclampsia. The studies on this subject are controversial. Cemgil et al. (22) detected that serum NGAL was decreased in women with preeclampsia compared to the control group and there was no significant difference in NGAL levels between mild and severe preeclampsia groups. They suggested that the serum NGAL was low in preeclampsia due to its antiinflammatory role. Cao et al. (23) have shown that serum and placental NGAL levels were significantly higher in women with preeclampsia compared to controls, however, there was no association with disease severity. Kim et al. (6) and Artunc-Ulkumen et al. (24) reported that serum NGAL was increased in women with preeclampsia compared to the controls and in women with severe preeclampsia compared to the women with mild preeclampsia. Artunc-Ulkumen et al. (24) suggested that generalized endothelial injury and persistent inflammation in severe preeclampsia may be responsible for the elevated levels of NGAL.

Sachan et al. (25) have shown that serum NGAL was increased in women with preeclampsia compared to the controls, in women with eclampsia compared to severe preeclampsia, in women with severe preeclampsia compared to the women with mild preeclampsia.

Simonazzi et al. (26) detected that serum NGAL was increased in women with preeclampsia compared to the controls, however, there was no association between serum NGAL and severity of preeclampsia. They also evaluated urine NGAL levels and found no difference between preeclampsia and control groups.

D’Anna et al. (13), Stepan et al. (19), Artunc-Ulkumen et al. (24) and Sachan et al. (25) detected that NGAL had a positive correlation with systolic and diastolic blood pressure, in accordance with results of our study.

D'Anna et al. $(13,15)$ observed that serum NGAL had a positive correlation with proteinuria in preeclampsia. Stepan et al. (19) and Dogan et al. (21) detected that serum NGAL had a positive correlation with serum creatinine in preeclamp- 
tic women. Cao et al. (23) have shown that serum NGAL had a positive correlation with proteinuria and uric acid. ArtuncUlkumen et al. (24) reported that serum NGAL had a positive correlation with proteinuria in spot urine and 24-hour urine tests. Sachan et al. (25) detected that serum NGAL had a positive correlation with blood urea nitrogen, creatinine, and uric acid; and serum NGAL levels were significantly higher in oliguric compared to non-oliguric pregnant women. Simonazzi et al. (26) found that urine NGAL had a positive correlation with a 24-hour urine test. In our study, serum NGAL had a positive correlation with serum urea $(\mathrm{r}=0.416$, $p=0.031$ ) however had no significant correlation with uric acid and amount of proteinuria in women with preeclampsia.

Xiao et al. (27) performed a study in 2013 and detected that urine NGAL, serum cystatin $\mathrm{C}$, urine RBP and urine KIM-1 were significantly elevated in women with preeclampsia. Ødum et al. (28) detected that urine NGAL levels were significantly elevated in healthy pregnant women compared to women with preeclampsia. Patel et al. (29) have detected that serum NGAL was significantly higher in women with acute renal injury due to hypertensive disorders of pregnancy compared to healthy pregnant women. They found that serum NGAL had a positive correlation with systolic and diastolic blood pressure, serum creatinine and proteinuria. Wang et al. (20) evaluated the association with serum NGAL levels and acute renal injury in preeclampsia and did not find any significant difference. Finally, Kelly et al. (30) evaluated the pregnant women with type I diabetes mellitus without microalbuminuria and shown that urinary NGAL was significantly increased in women with preeclampsia compared to the women without preeclampsia, which shows renal injury.

Kim et al. (6) have shown that there were no statistical correlations between the NGAL concentrations and birth weight. On the other hand, Artunc-Ulkumen et al. (24) observed that serum NGAL had a negative correlation with birth-weight, and 1- and 5-min Apgar scores.

Escouto et al. (31) evaluated serum NGAL levels in women with preeclamptic pregnancies, 6 weeks after delivery, and found that serum NGAL cannot predict cardiovascular risk.

\section{Conclusion}

In our study, serum NGAL was significantly higher in women with preeclampsia compared to the women without preeclampsia, in women with EOPE compared to the women LOPE, and in women with LOPE compared to women without preeclampsia. Mean serum NGAL levels were comparable in the preeclampsia with and without severe features groups. The correlation analysis showed that NGAL was not affected by age or BMI. NGAL had a positive correlation with systolic and diastolic blood pressure and the umbilical artery PI and RI. Serum NGAL had a positive correlation with serum urea however had no significant correlation with birth-weight,
Apgar scores, uric acid and amount of proteinuria in women with preeclampsia.

Acknowledgments: None

Funding: None.

Conflict of Interest Statement: The authors have no conflict of interest.

Author contributions: OG: Project development, manuscript writing, statistical analyses. NT: Data collection or management. MO: Data collection or management. SA: Data analysis. HE: Biochemical analyses. AT: Protocol/project development, data analysis, manuscript writing/editing

\section{References}

1. ACOG Practice Bulletin No. 202: Gestational hypertension and preeclampsia. Obstet Gynecol. 2019; 133(1):e1e25. doi: 10.1097/AOG.0000000000003018.

2. Walker JJ. Pre-eclampsia. Lancet. 2000;356(9237):12605. doi: 10.1016/S0140-6736(00)02800-2.

3. Raymond D, Peterson E. A critical review of early-onset and late-onset preeclampsia. Obstet Gynecol Surv. 2011;66(8):497-506. doi: 10.1097/OGX.0b013e3182331 028 .

4. Sibai BM. Maternal and uteroplacental hemodynamics for the classification and prediction of preeclampsia hypertension. 2008;52:805-6. doi: 10.1161/HYPERTENSIONAHA.108.119115

5. Valensise H, Vasapollo B, Gagliardi G, Novelli GP. Early and late preeclampsia: two different maternal hemodynamic states in the latent phase of the disease. Hypertension. 2008;52(5):873-80. doi: 10.1161/HYPERTENSIONAHA.108.117358.

6. Kim SM, Park JS, Norwitz ER, Jung HJ, Kim BJ, Park $\mathrm{CW}$, et al. Circulating levels of neutrophil gelatinase-associated lipocalin (NGAL) correlate with the presence and severity of preeclampsia. Reprod Sci. 2013;20(9):1083-9. doi: $10.1177 / 1933719113477480$

7. Haase M, Bellomo R, Devarajan P, Schlattmann P, HaaseFielitz A; NGAL Meta-analysis Investigator Group. The accuracy of neutrophil gelatinase-associated lipocalin (NGAL) in diagnosis and prognosis in acute kidney injury: a systematic review and meta-analysis. Am J Kidney Dis. 2009;54(6):1012-24. doi: 10.1053/j.ajkd.2009.07.020

8. Mishra J, Dent C, Tarabishi R, Mitsnefes MM, Ma Q, Kelly C, Ruff SM, Zahedi K, Shao M, Bean J, Mori K, Barasch J, Devarajan P: Neutrophil gelatinase-associated lipocalin (NGAL) as a biomarker for acute renal injury after cardiac surgery. Lancet. 2005;365(9466):1231-8. doi: 10.1016/S0140-6736(05)74811-X

9. Scazzochio E, Munmany M, Garcia L, Meler E, Crispi F, Gratacos E, et al. Prognostic role of maternal neutrophil gelatinase-associated lipocalin in women with severe early-onset preeclampsia. Fetal Diagn Ther. 2014;35(2): 127-32. doi: 10.1159/000356499 
10. Huang J, Wolk JH, Gewitz MH, Mathew R. Caveolin-1 expression during the progression of pulmonary hypertension. Exp Biol Med (Maywood). 2012;237(8): 956-65. doi: 10.1258/ebm.2012.011382

11. Viechtbauer W, Smits L, Kotz D, Budé L4, Spigt M5, Serroyen J, et al. A simple formula for the calculation of sample size in pilot studies. J Clin Epidemiol. 2015; 68(11):1375-9. doi: 10.1016/j.jclinepi.2015.04.014

12. Edelstam G, Löwbeer C, Kral G, Gustafsson SA, Venge P. New reference values for routine blood samples and human neutrophilic lipocalin during third-trimester pregnancy. Scand J Clin Lab Invest. 2001;61(8):583-92. doi: $10.1080 / 003655101753267937$.

13. D'Anna R, Baviera G, Giordano D, Todarello G, Corrado F, Buemi M. Second trimester neutrophil gelatinase-associated lipocalin as a potential prediagnostic marker of preeclampsia. Acta Obstet Gynecol Scand. 2008;87(12): 1370-3. doi: 10.1080/00016340802464463.

14. D'Anna R, Baviera G, Giordano D, Russo S, Dugo N, Santamaria A, et al. First trimester serum PAPP-A and NGAL in the prediction of late-onset pre-eclampsia. Prenat Diagn. 2009;29(11):1066-8. doi: 10.1002/pd.2339.

15. D'Anna R, Baviera G, Giordano D, Todarello G, Russo S, Recupero S, et al. Neutrophil gelatinase-associated lipocalin serum evaluation through normal pregnancy and in pregnancies complicated by preeclampsia. Acta Obstet Gynecol Scand. 2010;89(2):275-8. doi: 10.3109/0001634 0903443676.

16. D'Anna R, Santamaria A, Interdonato ML, Licata G, Giordano D. L9. NGAL, an early marker of endothelial dysfunction in preeclampsia. Pregnancy Hypertens. 2011;1 (3-4):243. doi: 10.1016/j.preghy.2011.08.010.

17. Youssef A, Righetti F, Morano D, Rizzo N, Farina A. Uterine artery Doppler and biochemical markers (PAPPA, PIGF, sFlt-1, P-selectin, NGAL) at $11+0$ to $13+16$ weeks in the prediction of late ( $>34$ weeks) pre-eclampsia. Prenat Diagn. 2011;31(12):1141-6. doi: 10.1002/ pd.2848.

18. Karampas GA, Eleftheriades MI, Panoulis KC, Rizou MD, Haliassos AD, Metallinou DK, et al. Prediction of pre-eclampsia combining NGAL and other biochemical markers with Doppler in the first and/or second trimester of pregnancy. A pilot study. Eur J Obstet Gynecol Reprod Biol. 2016;205:153-7. doi: 10.1016/j.ejogrb.2016.08.034.

19. Stepan H, Philipp A, Reiche M, Klostermann K, Schrey S, Reisenbüchler C, et al. Serum levels of the adipokine lipocalin-2 are increased in preeclampsia. J Endocrinol Invest. 2010;33(9):629-32. doi: 10.1007/BF03346661.

20. Wang Y, Gu Y, Loyd S, Jia X, Groome LJ. Increased urinary levels of podocyte glycoproteins, matrix metallopeptidases, inflammatory cytokines, and kidney injury biomarkers in women with preeclampsia. Am J Physiol Renal Physiol.2015;309(12):F1009-17. doi: 10.1152/ajprenal. 00257.2015
21. Dogan N, Yildirmaki S, Mihmanli V, Vardar M, Ozbanazi YG, Cakmak M, et al. Serum neutrophil gelatinase associated lipocalin and plasma nitric oxide levels in healthy and preeclamptic pregnants. Clin Exp Obstet Gynecol. 2014;41(6):700-3.

22. Cemgil Arikan D, Ozkaya M, Adali E, Kilinc M, Coskun A, Ozer A, et al. Plasma lipocalin-2 levels in pregnant women with pre-eclampsia, and their relation with severity of disease. J Matern Fetal Neonatal Med. 2011; 24(2): 291-6. doi: 10.3109/14767058.2010.487138.

23. Cao WH, Chen WP, Li J, Ye YH. [Correlation of lipoca lin-2 and its receptor expressions with preeclampsia]. Zhonghua Fu Chan Ke Za Zhi. 2012;47(6):418-21.

24. Artunc-Ulkumen B, Guvenc Y, Goker A, Gozukara C. Relationship of neutrophil gelatinase-associated lipocalin (NGAL) and procalcitonin levels with the presence and severity of the preeclampsia. J Matern Fetal Neonatal Med. 2015;28(16):1895-900. doi: 10.3109/14767058. 2014.972926.

25. Sachan R, Patel ML, Gaurav A, Gangwar R, Sachan P. Correlation of serum neutrophil gelatinase associated lipocalin with disease severity in hypertensive disorders of pregnancy. Adv Biomed Res. 2014;3:223. doi: 10.4103/ 2277-9175.145690.

26. Simonazzi G, Capelli I, Curti A, Comai G, Rizzo N, La Manna G. Serum and urinary neutrophil gelatinase-associated lipocalin monitoring in normal pregnancy versus pregnancies complicated by pre-eclampsia. In Vivo. 2015;29(1):117-21.

27. Xiao J, Niu J, Ye X, Yu Q, Gu Y. Combined biomarkers evaluation for diagnosing kidney injury in preeclampsia. Hypertens Pregnancy. 2013;32(4):439-49. doi: 10.3109/ 10641955.2013.827203.

28. Ødum L, Andersen AS, Hviid TV. Urinary neutrophil gelatinase-associated lipocalin (NGAL) excretion increases in normal pregnancy but not in preeclampsia. Clin Chem Lab Med. 2014;52(2):221-5. doi: 10.1515/cclm2013-0547.

29. Patel ML, Sachan R, Gangwar R, Sachan P, Natu S. Correlation of serum neutrophil gelatinase-associated lipocalin with acute kidney injury in hypertensive disorders of pregnancy. Int $\mathrm{J}$ Nephrol Renovasc Dis. 2013;6:181-6. doi: 10.2147/IJNRD.S45523.

30. Kelly CB, Hookham MB, Yu JY, Jenkins AJ, Nankervis AJ, Hanssen KF, et al. Subclinical first trimester renal abnormalities are associated with preeclampsia in normoalbuminuric women with type 1 diabetes. Diabetes Care. 2018;41(1):120-7. doi: 10.2337/dc17-1635.

31. Escouto DC, Green A, Kurlak L, Walker K, Loughna P, Chappell L, et al. Postpartum evaluation of cardiovascular disease risk for women with pregnancies complicated by hypertension. Pregnancy Hypertens. 2018;13:218-24. doi: 10.1016/j.preghy.2018.06.019 